\title{
REVOLVIMENTO OCASIONAL E CALAGEM EM LATOSSOLO MUITO ARGILOSO EM SISTEMA PLANTIO DIRETO CONSOLIDADO
}

\author{
Jonez Fidalski ${ }^{(1)^{*}}$, Renato Yagi ${ }^{(2)}$ e Cássio Antonio Tormena ${ }^{(3)}$ \\ (1) Instituto Agronômico do Paraná, Área de Solos, Paranavaí, Paraná, Brasil. \\ (2) Instituto Agronômico do Paraná, Área de Solos, Ponta Grossa, Paraná, Brasil. \\ (3) Universidade Estadual de Maringá, Departamento de Agronomia, Maringá, Paraná, Brasil. \\ * Autor correspondente. \\ E-mail: fidalski@iapar.br
}

\section{RESUMO}

A ocorrência de concentração de nutrientes e compactação superficial tem sido relatada após longo tempo de implantação do sistema plantio direto. $O$ objetivo deste estudo foi avaliar os atributos químicos, a densidade do solo e a produtividade das culturas subsequentes a uma única intervenção mecânica complementada com calagem de um Latossolo Vermelho Distroférrico textura muito argilosa conduzido em sistema plantio direto há 17 anos ininterruptos, em Pato Branco, no sudoeste do Paraná. O delineamento experimental utilizado foi de blocos ao acaso no esquema de parcelas subdivididas, com aração e gradagem do solo nas parcelas (sem e com revolvimento do solo com aração a 0,00-0,20 m e gradagem) e calagem nas subparcelas (sem e com calagem para elevar o índice de saturação por bases a 70 \%). Foram avaliados a densidade do solo e a produtividade das culturas de milho ( $6^{\circ}$ mês), biomassa de aveia-preta $\left(12^{\circ}\right.$ mês) e soja $\left(20^{\circ}\right.$ mês) e os atributos químicos do solo $\left(6^{\circ}\right.$ mês $)$. O revolvimento ocasional do solo com aração e gradagem em sistema plantio direto consolidado teve duração efêmera de seis meses na redução da densidade do solo. A incorporação do calcário não apresentou vantagens em relação à sua aplicação na superfície do solo. Não houve aumentos de produtividade das culturas subsequentes à calagem e ao revolvimento do solo. As produtividades das culturas de milho, aveia-preta e soja não dependeram do revolvimento e da incorporação de calcário nessa área agrícola.

Palavras-chave: compactação do solo, densidade do solo, acidez do solo, manejo do solo. 


\title{
ABSTRACT: OCCASIONAL SOIL TURNOVER AND LIMING IN A CLAYEY OXISOL UNDER A CONSOLIDATED NO-TILLAGE SYSTEM
}

\begin{abstract}
Accumulation of nutrients and surface compaction have been reported after a long time under a no-tillage system. The aim of this study was to evaluate soil chemical properties, bulk density, and crop yield following a single mechanical intervention associated with liming in a clayey Oxisol under a NT system for 17 consecutive years in Pato Branco, southwestern Paraná, Brazil. A randomized block experimental design was used in a split-plot arrangement, with plowing and harrowing of the soil in the plots (with and without soil turnover through plowing to 0.00-0.20 $\mathrm{m}$ and harrowing), and liming in the subplots (with and without liming to raise the level of base saturation to $70 \%$ ). Soil bulk density and yield of maize (6 $6^{\text {th }}$ month), black oat biomass (12th month), and soybean (20th month), as well as soil chemical properties (6 $6^{\text {th }}$ month), were evaluated. Occasional soil tillage through plowing and harrowing in a notillage system consolidated had a brief effect of reducing soil bulk density for six months. Incorporation of lime showed no advantages over application of lime on the soil surface. There were no yield increases in the crops following liming and soil tillage. The yields of corn, oat, and soybean did not depend on plowing and lime incorporation in this agricultural area.
\end{abstract}

Keywords: soil compaction, soil bulk density, soil acidity, soil management.

\section{INTRODUÇÃO}

Operações de aração e gradagem foram paradigmas no manejo dos solos agrícolas no passado, assim como se consolidou o não revolvimento do solo em sistema plantio direto (SPD), uma das razões para se distinguir o sistema como um todo da semeadura direta ou do plantio direto em si. Assim, o gradiente químico de solos em SPD, caracterizado pelo acúmulo de nutrientes na camada superficial, pode interferir na manutenção da estabilidade da produção agrícola particularmente em condições que predispõem as plantas ao estresse hídrico (Klein, 2011). Nessas condições, um revolvimento ocasional de solo em plantio direto, realizado uma única vez em área com 10 ou mais anos, pode aumentar a produtividade das culturas com a redistribuição da matéria orgânica e dos nutrientes em profundidade no perfil do solo (Quincke et al., 2007).

Sob estresse hídrico, as produtividades de milho e soja em plantio direto após escarificação foram inferiores ao SPD contínuo, o que Debiase et al. (2010) atribuíram às menores populações de plantas em razão da menor germinação das sementes decorrente da reduzida disponibilidade de água na camada superficial revolvida. A produtividade das culturas tem sido influenciada de modos diversos pela escarificação do solo em plantio direto, incrementando-as (Secco et al., 2005; Nicoloso et al., 2008), diminuindo-as (Collares et al., 2008; Debiase et al., 2010; Kunz et al., 2013) ou sendo indiferentes em relação ao SPD mantido continuamente (Lima et al., 2006; Klein e Camara, 2007; Quincke et al., 2007; Girardello et al., 2011). As alterações físicas de descompactação do solo em plantio direto por meio de escarificador têm duração efêmera, não sendo verificadas após 12 meses (Silva et al., 2012) ou após 18 meses das intervenções mecânicas (Mahl et al., 2008; Silveira Junior et al., 2012).
Se, por um lado, a incorporação de corretivos com aração e gradagem aumenta os riscos de ocorrência de erosão hídrica (Klein, 2011), por outro lado, as arações e gradagens com SPD podem ser empregadas para a correção da acidez em profundidade, a fim de diminuir substancialmente a compactação do solo pelo aumento da macroporosidade e da aeração bem como para reduzir a resistência do solo à penetração das raízes (Marcolan et al., 2007).

Em SPD recém-implantado, não houve diferenças significativas em produtividades de grãos de soja por quatro safras entre os tratamentos com aplicação de calcário na superfície do solo e incorporação do corretivo com arado e grade (Oliveira e Pavan, 1996). Em área há quatro anos em SPD, a incorporação de calcário com arado e grade foi eficiente na correção da acidez do solo em subsuperfície (0,10-0,20 m) em relação ao SPD mantido continuamente, mas não houve diferenças nas produtividades de soja, milho e trigo entre os tratamentos com incorporação ou não do calcário (Rossato et al., 2009). Com a incorporação de calcário a cada quatro anos, com arado e grade, em solo em SPD durante 12 anos, não foram observadas diferenças em produtividades de grãos de milho e de massa de matéria seca de aveia e ervilhaca, em relação ao SPD com aplicação de calcário na superfície do solo (Marcolan e Anghinoni, 2006).

Em áreas com cerca de seis e 10 anos em SPD, intervenções mecânicas com arados de disco ou aiveca não propiciaram aumentos de produtividade de grãos de sorgo, milho e soja em relação às áreas em SPD contínuo (Quincke et al., 2007). Nessas mesmas áreas, avaliações subsequentes das produtividades de milho e soja em rotação por três anos não apresentaram diferenças entre os tratamentos (Wortmann et al., 2010).

A hipótese deste trabalho é que o revolvimento ocasional e a calagem de um Latossolo muito argiloso 
em SPD consolidado aumentem a produtividade das culturas em razão da redução da densidade do solo (Ds) e redistribuição de sua fertilidade.

O objetivo deste estudo foi avaliar a Ds e os atributos químicos do solo e a produtividade das culturas subsequentes a uma única intervenção mecânica complementada com calagem de um Latossolo Vermelho Distroférrico conduzido em SPD há 17 anos, em Pato Branco, no sudoeste do Paraná.

\section{MATERIAL E MÉTODOS}

O experimento foi implantado em área cultivada em SPD há 17 anos ininterruptos, onde haviam sido realizadas rotações de culturas preconizadas pelo Iapar para o manejo de SPD com qualidade (Casão Junior et al., 2006), na Estação Experimental do Instituto Agronômico do Paraná (Iapar), em Pato Branco, região sudoeste do Paraná ( $26^{\circ} 07^{\prime} 16^{\prime \prime}$ de latitude sul e $52^{\circ} 39^{\prime} 37^{\prime \prime}$ de longitude oeste; e altitude de $730 \mathrm{~m}$ ). O tipo climático é o Cfa conforme a classificação de Köppen, com dados mensais de temperatura e precipitação pluvial apresentados na figura 1. O solo da área experimental é um Latossolo Vermelho Distroférrico típico (Santos et al., 2013), com textura muito argilosa ( $620 \mathrm{~g} \mathrm{~kg}^{-1}$ de argila, 330 $\mathrm{g} \mathrm{kg}^{-1}$ de silte e $50 \mathrm{~g} \mathrm{~kg}^{-1}$ de areia), sob relevo plano a suave ondulado, com fertilidade e Ds na camada de 0,00-0,20 m (Quadro 1).

O delineamento utilizado foi de blocos ao acaso no esquema de parcelas subdivididas, com quatro repetições. O revolvimento (sem e com revolvimento do solo) foi alocado nas parcelas, e a calagem (sem e com 1,7 Mg ha-1 de calcário dolomítico PRNT $100 \%$ para elevar o índice de saturação por bases a $70 \%$ ) foi alocada nas subparcelas. As subparcelas tinham $44 \mathrm{~m}^{2}$ (7 $\mathrm{m}$ de comprimento e 6,3 $\mathrm{m}$ de largura), separadas com carreadores de $1 \mathrm{~m}$ de largura, e carreadores de $6 \mathrm{~m}$ entre os blocos para o trânsito de tratores e implementos para aplicações de agroquímicos.

O revolvimento do solo foi realizado em 13/10/2009 e consistiu de uma aração (arado de quatro discos com $0,81 \mathrm{~m}$ de diâmetro) seguida de gradagem niveladora (grade niveladora com 32 discos com $0,35 \mathrm{~m}$ de diâmetro), previamente reguladas e testadas para o revolvimento do solo a $0,20 \mathrm{~m}$ de profundidade. Em 14/10/2009, semeou-se milho P30F53, híbrido simples precoce, no espaçamento de 0,90 m. Após a colheita do milho e em 30/04/2010, foi realizada a semeadura de aveia-preta, cultivar IAPAR 61 Ibiporã, no espaçamento de $0,20 \mathrm{~m}$ com 350 sementes puras viáveis por $\mathrm{m}^{2}$. No pleno florescimento, a aveia-preta foi dessecada para

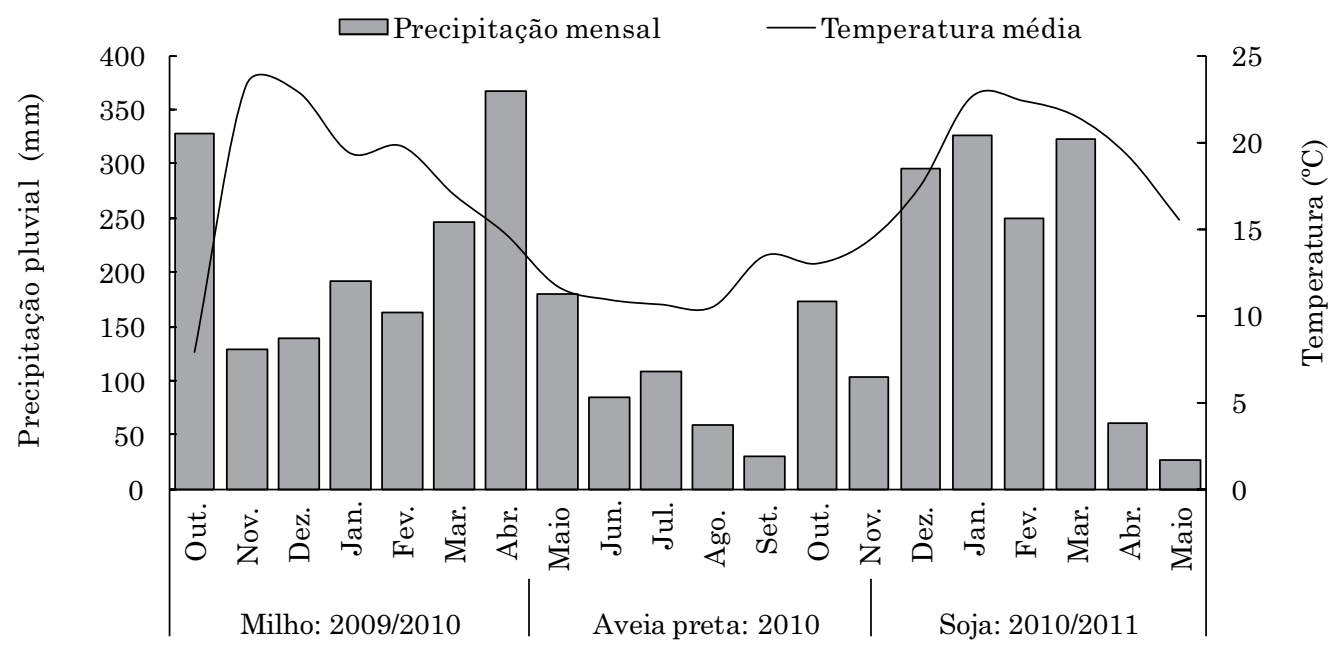

Figura 1. Precipitação pluvial mensal e temperatura mensal média durante o período experimental, em área de Latossolo Vermelho Distroférrico típico há 17 anos ininterruptos em sistema de plantio direto (SPD).

Quadro 1. Caracterização química e densidade do solo (Ds) na camada de 0,00-0,20 m de um Latossolo Vermelho Distroférrico típico, em outubro de 2009, antes da implantação dos tratamentos

\begin{tabular}{|c|c|c|c|c|c|c|c|c|}
\hline C(1) & $\mathbf{P}^{(2)}$ & $\mathrm{pH}\left(\mathrm{CaCl}_{2}\right)^{(3)}$ & $\mathrm{H}+\mathrm{Al}(4)$ & $\mathbf{K}^{+(2)}$ & $\mathrm{Ca}^{2+(5)}$ & $\mathrm{Mg}^{2+(5)}$ & $\mathrm{V}$ & Ds \\
\hline $\mathrm{g} \mathrm{dm}^{-3}$ & $\mathrm{mg} \mathrm{dm}{ }^{-3}$ & & \multicolumn{4}{|c|}{$\mathrm{cmol}_{\mathrm{c}} \mathrm{dm}^{-3}$} & $\%$ & $\mathrm{Mg} \mathrm{m}^{-3}$ \\
\hline 23 & 24 & 4,80 & 5,25 & 0,16 & 4,79 & 2,10 & 57,31 & 1,28 \\
\hline
\end{tabular}

(1) Método Walkley-Black. (2) Extrator Mehlich-1. (3) $\mathrm{pH}$ em solução de $\mathrm{CaCl}_{2} 0,01$ mol L-1. (4) Extrator acetato de cálcio 0,5 mol L-1 a pH 7,0. (5) Extrator KCl $1 \mathrm{~mol} \mathrm{~L}^{-1}$. 
semeadura subsequente da cultura da soja, semeada em 12/11/2010, cultivar CD 202, com entrelinhas no espaçamento de $0,45 \mathrm{~m}$.

As amostragens de solo para avaliar a Ds foram coletadas com um extrator para cilindros metálicos $(0,05 \mathrm{~m}$ de altura e $0,05 \mathrm{~m}$ de diâmetro), no centro das camadas de $0-0,10$ e $0,10-0,20 \mathrm{~m}$, onde foram introduzidos verticalmente no solo com velocidade constante por meio de um esticador hidráulico com capacidade de 10 t, apoiado no contrapeso dianteiro de um trator. Essas coletas de solo foram feitas durante o desenvolvimento da cultura de milho (novembro/2009 e $1^{\circ}$ mês após a escarificação e calagem) e após os cultivos de milho (abril $/ 2010$ e $6^{\circ}$ mês após o revolvimento do solo e calagem), aveia-preta (outubro/2010 e $12^{\circ}$ mês após o revolvimento do solo e calagem) e soja (junho/2011 e $20^{\circ}$ mês após o revolvimento do solo e calagem). As amostras com estrutura preservada de solo foram colocadas em estufa a $105^{\circ} \mathrm{C}$ por $48 \mathrm{~h}$ para obter a massa de solo seco e calcular a Ds (Donagema et al., 2011). A avaliação dos atributos químicos do solo foi realizada no final do cultivo de milho, em abril de 2010, por meio da coleta de 10 subamostras por parcela experimental nas camadas de 0,00-0,10 e 0,10-0,20 m; em seguida, foram feitas as análises químicas, conforme descrito por Pavan et al. (1992).

$\mathrm{O}$ milho foi colhido em sete linhas de $7 \mathrm{~m}$ com espaçamento entrelinhas de $0,90 \mathrm{~m}$ das três linhas centrais menos $1 \mathrm{~m}$ de cada extremidade das subparcelas. A aveia-preta foi colhida em duas porções de $0,25 \mathrm{~m}^{2}$ por subparcela. A soja foi colhida em quatro linhas centrais menos $1 \mathrm{~m}$ de cada extremidade. Quantificaram-se a produtividade de grãos para as culturas de milho (2009/10) e soja (2010/11), e a biomassa da parte aérea de aveia-preta (2010).

Os dados foram submetidos às análises de variâncias por meio do modelo matemático de blocos ao acaso no esquema de parcelas subdivididas, utilizando-se as parcelas (revolvimento) e as subparcelas (calagem), com quatro repetições, independentemente para as épocas de avaliações e camadas de solo. As médias foram comparadas pelo teste de Tukey a $5 \%$ conforme Banzatto e Kronka (2006).

\section{RESULTADOS E DISCUSSÃO}

Não houve interação entre os manejos de solo e a calagem $(p \leq 0,05)$; foram verificados somente efeitos independentes de revolvimento sobre a Ds (Quadro 2) e de revolvimento ou calagem para alguns atributos químicos do solo (Quadro 3).

O revolvimento do solo com aração e gradagem diminuiu a Ds da camada de 0,00-0,10 $\mathrm{m}$ aos seis meses e de 0,10-0,20 $\mathrm{m}$ apenas no $1^{\circ}$ mês após intervenção mecânica (Quadro 2). Os resultados deste estudo
Quadro 2. Densidade do solo no $1^{\circ}, 6^{\circ}, 12^{\circ}$ e $20^{\circ}$ meses após os tratamentos de revolvimento do solo e calagem com arado de discos e grade niveladora em sistema plantio direto consolidado há 17 anos em Latossolo Vermelho Distroférrico típico

\begin{tabular}{lcccc}
\hline \multirow{2}{*}{ Tratamento } & \multicolumn{4}{c}{ Mês após revolvimento e calagem } \\
\cline { 2 - 5 } & $\mathbf{1}^{\mathbf{o}}$ & $\mathbf{6}^{\mathbf{o}}$ & $\mathbf{1 2}^{\mathbf{o}}$ & $\mathbf{2 0}^{\circ}$ \\
\cline { 2 - 5 } & \multicolumn{4}{c}{$\mathrm{Mg} \mathrm{m}{ }^{-3}$} \\
Sem revolvimento & $1,26 \mathrm{a}$ & $1,25 \mathrm{a}$ & $1,22 \mathrm{a}$ & $1,20 \mathrm{a}$ \\
Com revolvimento & $1,15 \mathrm{~b}$ & $1,17 \mathrm{~b}$ & $1,11 \mathrm{a}$ & $1,19 \mathrm{a}$ \\
Sem calagem & $1,20 \mathrm{~A}$ & $1,23 \mathrm{~A}$ & $1,17 \mathrm{~A}$ & $1,21 \mathrm{~A}$ \\
Com calagem & $1,21 \mathrm{~A}$ & $1,19 \mathrm{~A}$ & $1,16 \mathrm{~A}$ & $1,19 \mathrm{~A}$ \\
& & $0,10-0,20 \mathrm{~m}$ & \\
Sem revolvimento & $1,30 \mathrm{a}$ & $1,24 \mathrm{a}$ & $1,23 \mathrm{a}$ & $1,24 \mathrm{a}$ \\
Com revolvimento & $1,23 \mathrm{~b}$ & $1,21 \mathrm{a}$ & $1,16 \mathrm{a}$ & $1,19 \mathrm{a}$ \\
Sem calagem & $1,28 \mathrm{~A}$ & $1,23 \mathrm{~A}$ & $1,21 \mathrm{~A}$ & $1,24 \mathrm{~A}$ \\
Com calagem & $1,25 \mathrm{~A}$ & $1,22 \mathrm{~A}$ & $1,18 \mathrm{~A}$ & $1,19 \mathrm{~A}$ \\
\hline
\end{tabular}

Médias seguidas da mesma letra, dentro da mesma camada de solo, mês, revolvimento (letras minúsculas) e calagem (letras maiúsculas), não diferem entre si pelo teste de Tukey a $5 \%$.

apresentaram alterações físicas de descompactação com menor tempo de duração comparado com o obtido por outros autores (Quincke et al., 2007; Tormena et al., 2007; Mahl et al., 2008; Wortmann et al., 2010; Silva et al., 2012; Silveira Junior et al, 2012).

Em vista da duração efêmera das alterações físicas de descompactação com a escarificação do solo, que não ultrapassam 12 meses (Silva et al., 2012) ou 18 meses (Silveira Junior et al., 2012) das intervenções mecânicas, a expectativa de que o revolvimento por meio de aração e gradagem, promoveria e prolongaria a descompactação do solo não foi confirmada; pelo contrário, esse apresentou-se inferior com efeito limitado a seis meses (Quadro 2). Avaliações da Ds após 2 (Quincke et al., 2007) e 5 anos (Wortmann et al., 2010) de intervenções mecânicas com escarificador e arados de disco e aivecas não apresentaram diferenças com área mantida continuamente em SPD.

De modo similar, Drescher et al. (2011), ao avaliarem inversões mecânicas com arados de discos e grade de discos e com escarificador com rolo destorroador em SPD de oito anos, não observaram diferenças nas Ds até a profundidade de 0,25 m após 2,5 a 7,5 anos entre essas intervenções mecânicas e entre essas intervenções mecânicas e o SPD conduzido por 16 anos. Possivelmente, o rearranjamento natural do solo revolvido pelo preparo intensivo com arado e grade, associado ao SPD subsequente e ao trânsito de maquinários e implementos, proporciona esse efeito efêmero do revolvimento do solo, inferior aos relatados com escarificação mecânica.

A calagem, com ou sem incorporação de calcário ao solo, não influenciou a Ds em ambas as camadas (Quadro 2). Efeitos antagônicos da diminuição 
Quadro 3. Atributos químicos do solo após seis meses dos tratamentos de revolvimento do solo e calagem com arado de discos e grade niveladora em sistema plantio direto (SPD) consolidado há 17 anos em Latossolo Vermelho Distroférrico típico

\begin{tabular}{|c|c|c|c|c|c|c|c|c|}
\hline Tratamento & $\mathbf{C}(1)$ & $\mathbf{P}(2)$ & $\mathrm{pH}\left(\mathrm{CaCl}_{2}\right)^{(3)}$ & $\mathrm{H}+\mathrm{Al}(4)$ & $\mathrm{K}^{+(2)}$ & $\mathrm{Ca}^{2+(5)}$ & $\mathrm{Mg}^{2+(5)}$ & $\mathrm{V}$ \\
\hline & $\mathrm{g} \mathrm{kg}^{-1}$ & $\mathrm{mg} \mathrm{kg}-1$ & & \multicolumn{4}{|c|}{$\mathrm{cmol}_{\mathrm{c}} \mathrm{dm}^{-3}$} & $\%$ \\
\hline & \multicolumn{8}{|c|}{$0,00-0,10 \mathrm{~m}$} \\
\hline Sem revolvimento & $26,5 \mathrm{a}$ & $19 \mathrm{a}$ & $4,80 \mathrm{a}$ & $5,74 \mathrm{a}$ & $0,59 \mathrm{a}$ & $4,15 \mathrm{a}$ & $1,80 \mathrm{a}$ & $53 \mathrm{a}$ \\
\hline Com revolvimento & $29,0 \mathrm{a}$ & $18 \mathrm{a}$ & $4,76 \mathrm{a}$ & $6,05 \mathrm{a}$ & $0,70 \mathrm{a}$ & $4,33 \mathrm{a}$ & $1,93 \mathrm{a}$ & $53 \mathrm{a}$ \\
\hline Sem calagem & $27,6 \mathrm{~A}$ & $16 \mathrm{~A}$ & $4,68 \mathrm{~B}$ & $6,02 \mathrm{~A}$ & $0,59 \mathrm{~A}$ & $4,05 \mathrm{~A}$ & $1,54 \mathrm{~B}$ & $51 \mathrm{~A}$ \\
\hline \multirow[t]{2}{*}{ Com calagem } & $27,9 \mathrm{~A}$ & $21 \mathrm{~A}$ & $4,89 \mathrm{~A}$ & $5,77 \mathrm{~A}$ & $0,70 \mathrm{~A}$ & $4,43 \mathrm{~A}$ & $2,19 \mathrm{~A}$ & $56 \mathrm{~A}$ \\
\hline & \multicolumn{8}{|c|}{$0,10-0,20 \mathrm{~m}$} \\
\hline Sem revolvimento & $25,0 \mathrm{~b}$ & $9 \mathrm{a}$ & $4,80 \mathrm{a}$ & $5,70 \mathrm{a}$ & $0,35 \mathrm{a}$ & 3,89 a & $1,83 \mathrm{a}$ & $51 \mathrm{a}$ \\
\hline Com revolvimento & $27,7 \mathrm{a}$ & $12 \mathrm{a}$ & $4,84 \mathrm{a}$ & $5,66 \mathrm{a}$ & $0,37 \mathrm{a}$ & $4,35 \mathrm{a}$ & $2,32 \mathrm{a}$ & $56 \mathrm{a}$ \\
\hline Sem calagem & $27,1 \mathrm{~A}$ & $10 \mathrm{~A}$ & $4,75 \mathrm{~A}$ & $5,87 \mathrm{~A}$ & $0,36 \mathrm{~A}$ & $3,93 \mathrm{~A}$ & $1,96 \mathrm{~A}$ & $52 \mathrm{~A}$ \\
\hline Com calagem & $25,6 \mathrm{~A}$ & $11 \mathrm{~A}$ & $4,89 \mathrm{~A}$ & $5,49 \mathrm{~A}$ & $0,36 \mathrm{~A}$ & $4,31 \mathrm{~A}$ & $2,20 \mathrm{~A}$ & $55 \mathrm{~A}$ \\
\hline
\end{tabular}

(1) Método Walkley-Black. (2) Extrator Mehlich-1. (3) $\mathrm{pH}$ em solução de $\mathrm{CaCl}_{2} 0,01 \mathrm{~mol} \mathrm{~L}^{-1}$. (4) Extrator acetato de cálcio 0,5 mol L-1 a pH 7,0. (5) Extrator $\mathrm{KCl} 1 \mathrm{~mol} \mathrm{~L}-1$. Médias seguidas da mesma letra, dentro da mesma camada de solo, revolvimento (letras minúsculas) e calagem (letras maiúsculas), não diferem entre si pelo teste deTukey a $5 \%$.

efêmera da Ds com o seu revolvimento e de possível aumento da Ds com a calagem, em razão do aumento da carga elétrica negativa líquida e da dispersão de argila (Albuquerque et al., 2000), podem explicar a ausência de efeitos da incorporação de calcário em sua densidade. Alterações na Ds após arações e gradagens a cada quatro anos para incorporação de calcário em SPD durante 12 anos, na camada de $0,15 \mathrm{~m}$ de um Argissolo Vermelho de textura arenosa, em relação ao SPD mantido continuamente durante esse mesmo período de tempo não foram observadas (Marcolan e Anghinoni, 2006). Para esses autores, o período de quatro anos foi suficiente para recuperação das condições edáficas do plantio direto após o revolvimento do solo.

O revolvimento do solo aumentou em $11 \%$ os teores de C orgânico do solo na camada de 0,10-0,20 m (Quadro 3), indicando que a incorporação de resíduos vegetais, sob as condições climáticas da área experimental, proporcionou a manutenção do $\mathrm{C}$ orgânico na superfície, bem como o aumento em subsuperfície. O revolvimento intensivo do solo possivelmente redistribuiu o $\mathrm{C}$ orgânico acumulado na superfície do solo depois de 17 anos de SPD (Quadro 3), fazendo com que também frações orgânicas mais recalcitrantes expostas na camada superficial de solo muito argiloso (620 $\mathrm{g} \mathrm{kg}^{-1}$ de argila) se mantivessem após intervenção mecânica. Entre sistemas de cultivo, o SPD possui formas de $\mathrm{C}$ orgânico mais lábeis na camada superficial e, invariavelmente, o grau de humificação ou a recalcitrância dos compostos orgânicos aumenta em profundidade em quaisquer sistemas de cultivo (Favoretto et al., 2008).

Cinco anos após aplicarem o revolvimento do solo com arado de aiveca em SPD, observou-se diminuição média de $16 \%$ nos teores de C orgânico na camada de 0,0-0,075 m em relação ao SPD contínuo (Kettler et al., 2000). Entretanto, e de forma similar a este trabalho, também observou-se aumento dos teores de $\mathrm{C}$ na camada subsuperficial do solo, de $12 \%$ na camada de 0,075-0,150 m. O revolvimento ocasional do solo em SPD com escarificador e arados de aiveca ou disco, ao redistribuírem os teores de $\mathrm{C}$ em profundidade, proporcionou pequeno incremento na liberação de C- $\mathrm{CO}_{2}$ do solo em relação ao SPD contínuo, sem perdas de C orgânico lábil (Quincke et al., 2007).

No entanto, a intervenção mecânica com preparo convencional de solo em SPD de mais de 20 anos tem resultado em menores estratificações de $\mathrm{C}$ no perfil de solo com menores teores de argila (Stockfisch et al., 1999; Vandenbygaart e Kay, 2004). Em regiões de clima temperado, mais de dois terços dos estoques de C em solo franco arenoso em SPD com baixos teores de C foram perdidos em poucas semanas após mobilização ocasional do solo (Vandenbygaart e Kay, 2004).

Não houve efeito do revolvimento do solo e da calagem para os demais atributos químicos do solo, com exceção do $\mathrm{pH}$ e dos teores de $\mathrm{Mg}^{2+}$, que aumentaram na camada de 0,00-0,10 $\mathrm{m}$ em razão da aplicação de calcário dolomítico ao solo, tanto com aplicação superficial quanto com incorporação desse corretivo (Quadro 3). A ausência de efeitos significativos do revolvimento do solo pode estar associada ao acúmulo de nutrientes a 0,00-0,20 m no período contínuo de 17 anos de SPD.

Em áreas com 11 e sete anos de SPD, Wortmann et al. (2010) não observaram diferenças entre o SPD contínuo e aquele em que o solo em SPD foi revolvido com arado de discos, nos teores de $\mathrm{P}$ (Mehlich-3) nas camadas de 0,00-0,05; 0,05-0,10; 
0,10-0,20; e 0,20-0,30 m. Nessas mesmas áreas e em relação a esses mesmos tratamentos, Garcia et al. (2007) não notaram diferenças nos teores de $\mathrm{P}$ (Bray-I) e $\mathrm{K}$ e nos valores de $\mathrm{pH}$. Diminuição da estratificação vertical e aumento do $\mathrm{pH}$ na camada com o revolvimento do solo com arado de aiveca foram observados por Kettler et al. (2000), o que foi atribuído à mistura de solo da superfície com o da superfície contendo carbonatos. É possível que a fertilidade do solo (0,00-0,20 m) encontrada com 17 anos de SPD tenha sido a provável causa da ausência de efeitos do revolvimento nos atributos químicos do solo.

Em comparação com o SPD mantido continuamente, a produtividade de grãos de milho e soja e a de biomassa da parte aérea de aveia-preta não foram influenciadas pelo revolvimento do solo e pela calagem (Quadro 4). Sem restrições hídricas (Figura 1), com diminuição efêmera na compactação preexistente do solo (Quadro 2) e os limitados efeitos da calagem e do revolvimento do solo nos atributos químicos a 0,00-0,20 m (Quadro 3), provavelmente são as justificativas para o resultado constatado. Esses resultados complementam e corroboram a informação de que a calagem em SPD a partir do revolvimento intensivo do solo não é vantajosa em qualquer período de condução do sistema.

Especificamente em relação à intervenção mecânica, há relatos de que não houve aumento das produtividades de grãos de milho após cinco anos de SPD, onde o solo foi revolvido com arado de discos (Stavi et al., 2011). Resultados similares foram obtidos com grãos de soja em SPD de oito anos em Latossolo Vermelho de textura argilosa, onde as intervenções mecânicas foram feitas com arado de discos, com grade de discos e escarificador com rolo destorroador, justificando-se estes resultados pela boa distribuição de chuvas que amenizaram o efeito prejudicial da compactação da camada subsuperficial do solo sobre o crescimento das raízes (Drescher et al., 2012).

Ausências de diferenças na produtividade das culturas em razão da calagem na superfície ou com incorporação de calcário em SPD foram encontradas em diferentes situações: recém-implantado (Oliveira e Pavan, 1996), em área há quatro anos em SPD (Rossato et al., 2009); por 12 anos, com reaplicações de calcário, incorporadas ou na superfície do solo, a cada quatro anos (Marcolan e Anghinoni, 2006); e após seis e 10 (Quincke et al., 2007) e 11 a 13 anos (Wortmann et al., 2010) da intervenção mecânica.

Não foram verificadas diferenças nas produtividades de grãos de milho e soja e de biomassa da parte aérea de aveia-preta pelo revolvimento do solo e da calagem (Quadro 4), em razão da ausência de restrições hídricas (Figura 1), da diminuição efêmera de seis meses na compactação preexistente do solo, proporcionados pelo revolvimento desse (Quadro 2) e dos pequenos efeitos da calagem na camada de 0,00-0,20 m (Quadro 3). Ausências de diferenças de produtividades das culturas em SPD foram constatadas seja pela intervenção mecânica (Stavi et al., 2011) ou pela incorporação de
Quadro 4. Massa de grãos de milho e soja, e massa da parte aérea de aveia-preta após os tratamentos de revolvimento do solo e calagem com arado de discos e grade niveladora em sistema plantio direto (SPD) consolidado há 17 anos em Latossolo Vermelho Distroférrico típico

\begin{tabular}{lccc}
\hline \multirow{2}{*}{ Tratamento } & Milho & Soja & Aveia-preta \\
\cline { 2 - 4 } & $\mathbf{2 0 0 9 / 1 0}$ & $\mathbf{2 0 1 0 / 1 1}$ & $\mathbf{2 0 1 0}$ \\
\cline { 2 - 4 } & \multicolumn{3}{c}{$\mathrm{kg} \mathrm{ha}^{-1}$} \\
Sem revolvimento & $10568 \mathrm{a}$ & $3811 \mathrm{a}$ & $5953 \mathrm{a}$ \\
Com revolvimento & $10387 \mathrm{a}$ & $3600 \mathrm{a}$ & $6096 \mathrm{a}$ \\
Sem calagem & $10313 \mathrm{~A}$ & $3548 \mathrm{~A}$ & $5949 \mathrm{~A}$ \\
Com calagem & $10642 \mathrm{~A}$ & $3863 \mathrm{~A}$ & $6100 \mathrm{~A}$ \\
\hline
\end{tabular}

Médias seguidas da mesma letra, dentro da mesma cultura, revolvimento (letras minúsculas) e calagem (letras maiúsculas), não diferem entre si pelo teste de Tukey a $5 \%$.

calcário ao solo (Oliveira e Pavan, 1986; Marcolan e Anghinoni, 2006; Quincke et al., 2007; Rossato et al., 2009; Wortmann et al., 2010).

A hipótese deste trabalho foi refutada porque a redução da Ds juntamente com as pequenas alterações dos atributos químicos do solo, após seis meses do seu revolvimento com aração e gradagem e calagem (Quadros 2 e 3), não promoveram aumentos de produtividade na cultura de milho e tampouco das culturas subsequentes no Latossolo Vermelho Distroférrico textura muito argilosa conduzido em SPD há 17 anos ininterruptos (Quadro 4). Isso significa que as produtividade na cultura de milho, aveia-preta e soja não dependiam do revolvimento e da incorporação de calcário nessa área agrícola.

\section{CONCLUSÕES}

O revolvimento ocasional do solo com aração e gradagem em sistema plantio direto consolidado teve duração efêmera de seis meses na redução da densidade do solo.

A incorporação do calcário não apresentou vantagens em relação à aplicação de calcário na superfície do solo.

Não houve aumentos de produtividade das culturas subsequentes à calagem e ao revolvimento do solo.

A produtividade das culturas de milho, aveia-preta e soja não dependiam do revolvimento e da incorporação de calcário nessa área agrícola.

\section{AGRADECIMENTOS}

À Fundação Araucária e ao CNPq, pelas bolsas de Produtividade em Pesquisa, respectivamente, ao primeiro e terceiro autores. 


\section{REFERÊNCIAS}

Albuquerque JA, Bayer C, Ernani PR, Fontana EC. Propriedades físicas e eletroquímicas de um Latossolo Bruno afetadas pela calagem. R Bras Ci Solo. 2000;24:295-300.

Banzatto DA, Kronka SN. Experimentação agrícola. $4^{\text {a }}$.ed. Jaboticabal: Funep; 2006.

Casão Junior R, Siqueira R, Mehta YR, Passini JJ. Sistema plantio direto com qualidade. Londrina: IAPAR, Foz do Iguaçú: Itaipu Binacional; 2006.

Collares GL, Reinert DJ, Reichert JM, Kaiser DR. Compactação de um Latossolo induzida pelo tráfego de máquinas e sua relação com o crescimento e produtividade de feijão e trigo. $\mathrm{R}$ Bras $\mathrm{Ci}$ Solo. 2008;32:933-42.

Debiase H, Levien R, Trein CR, Conte O, Kamimura KM. Produtividade de soja e milho após coberturas de inverno e descompactação mecânica do solo. Pesq Agropec Bras. 2010;45:603-12.

Donagema GK, Campos DVB, Calderano SB, Teixeira WG, Viana JHM. Manual de métodos de análise de solo. $2^{\mathrm{a}}$.ed. Rio de Janeiro: Embrapa-Solos; 2011. (Documentos/Embrapa Solos, 132). [Acessado em: 26 mar 2015]. Disponível em: http://ainfo. cnptia.embrapa.br/digital/bitstream/item/104933/1/Manual-deMetodos-de-Analise-de-Solo.pdf.

Drescher MS, Eltz FLF, Denardin JE, Faganello A, Drescher GL. Resistência à penetração e rendimento da soja após intervenção mecânica em Latossolo Vermelho sob plantio direto. R Bras Ci Solo. 2012;36:1836-44.

Drescher MS, Eltz FLF, Denardin JE, Faganello A. Persistência do efeito de intervenções mecânicas para a descompactação de solos sob plantio direto. R Bras Ci Solo. 2011;35:1713-22.

Favoretto CM, Gonçalves D, Milori DMBP, Rosa JA, Leite WC, Brinatti AM, Saab SC. Determination of humification degree of organic matter of an Oxisol and of its organo-mineral fractions. Quím Nova. 2008;31:1994-6.

Garcia JP, Wortmann CS, Mamo M, Drijber RA, Quincke JA, Tarkalson D. One-time tillage of no-till: Effects on nutrients, mycorrhizae, and phosphorus uptake. Agron J. 2007;99:1093-103.

Girardello VC, Amado TJC, Nicoloso RS, Horber T, Ferreira AO, Tabaldi FM, Lanzanova ME. Alterações nos atributos físicos de um Latossolo Vermelho sob plantio direto induzidas por diferentes tipos de escarificadores e o rendimento da soja. R Bras Ci Solo. 2011;35:2115-26.

Kettler TA, Lyon DJ, Doran JW, Powers WL, Stroup WW. Soil quality assessment after weed-control tillage in a no-till wheat-fallow cropping system. Soil Sci Soc Am J. 2000;64:339-46.

Klein VA, Camara RK. Rendimento da soja e intervalo hídrico ótimo em Latossolo Vermelho sob plantio direto escarificado. $\mathrm{R}$ Bras Ci Solo. 2007;31:221-7.

Klein VA. Gradiente químico de solos sob plantio direto: uma condição que limita a produtividade das plantas. R Plantio Direto. 2011;20:23-6.

Kunz M, Gonçalves ADMA, Reichert JM, Guimarães RML, Reinert DJ, Rodrigues MF. Compactação do solo na integração soja-pecuária de leite em Latossolo argiloso com semeadura direta e escarificação. R Bras Ci Solo. 2013;37:1699-708.

Lima CLR, Reinert JD, Reichert JM, Suzuki LEAS, Gubiani PI. Qualidade físico-hídrica e rendimento de soja (Glycine max L.) e feijão (Phaseolus vulgaris L.) de um Argissolo Vermelho distrófico sob diferentes sistemas de manejo. Ci Rural. 2006;36:1172-8.

Mahl D, Silva RB, Gamero CA, Silva PRA. Resistência do solo à penetração, cobertura vegetal e produtividade do milho em plantio direto escarificado. Acta Sci Agron. 2008;30:741-7.

Marcolan AL, Anghinoni I, Fraga TI, Leite JGDB. Recuperação de atributos físicos de um Argissolo em função do seu revolvimento e do tempo de semeadura direta. R Bras Ci Solo. 2007;31:571-9.

Marcolan AL, Anghinoni I. Atributos físicos de um Argissolo e rendimento de culturas de acordo com o revolvimento do solo em plantio direto. R Bras Ci Solo. 2006;30:163-70.

Nicoloso RS, Amado TJC, Schneider S, Lanzanova ME, Girardello VC, Bragagnolo J. Eficiência da escarificação mecânica e biológica na melhoria dos atributos físicos de um Latossolo muito argiloso e no incremento do rendimento de soja. R Bras Ci Solo. 2008;32:1723-34.

Oliveira EL, Pavan MA. Control of soil acidity in no-tillage system for soybean production. Soil Till Res. 1996;38:47-57.

Pavan MA, Bloch MF, Zempulski HC, Miyazawa M, Zocoler DC. Manual de análise química do solo e controle de qualidade. Londrina: Iapar; 1992. (Circular, 76).

Quincke JA, Wortmann CS, Mamo M, Franti R, Drijber RA, Garcia JP. One-time tillage of no-till systems: soil physical properties, phosphorus runoff, and crop yield. Agron J. 2007;99:1104-10.

Rossato OB, Ceretta CA, Silva LS, Brunetto G, Adorna JC, Girotto E, Lourenzi CR. Correction of soil acidity in the subsurface of an Oxisol with sandy loam texture under no-tillage. R Bras Ci Solo. 2009;33:659-67.

Santos HG, Jacomine PKT, Anjos LHC, Oliveira VA, Lumbreras JF, Coelho MR, Almeida JA, Cunha TJF, Oliveira JB. Sistema brasileiro de classificação de solos. $3^{a}$.ed. Brasília, DF: Embrapa; 2013.

Secco D, Ros CO, Secco JK, Fiorin JE. Atributos físicos e produtividade de culturas em um Latossolo Vermelho argiloso sob diferentes sistemas de manejo. R Bras Ci Solo. 2005;29:407-14.

Silva SGC, Silva ÁP, Giarola NFB, Tormena CA, Sá JCM. Temporary effect of chiseling on the compaction of a Rhodic Hapludox under no-tillage. R Bras Ci Solo. 2012;36:547-55.

Silveira Junior SD, Silva AP, Figueiredo GC, Tormena CA, Giarola NFB. Qualidade física de um Latossolo Vermelho sob plantio direto submetido à descompactação mecânica e biológica. R Bras Ci Solo. 2012;36:1854-67.

Stavi I, Lal R, Owens LB. On-farm effects of no-till versus occasional tillage on soil quality and crop yields in eastern Ohio. Agron Sustain Dev. 2011;31:475-82.

Stockfisch N, Forstreuterb T, Ehlers W. Ploughing effects on soil organic matter after twenty years of conservation tillage in Lower Saxony, Germany. Soil Till Res. 1999;52:91-101.

Tormena CA, Araújo MA, Fidalski J, Costa JM. Variação temporal do Intervalo Hídrico Ótimo de um Latossolo Vermelho Distroférrico sob sistemas de plantio direto. R Bras Ci Solo. 2007;31:211-9.

Vandenbygaart AJ, Kay BD. Persistence of soil organic carbon after plowing a long-term no-till field in southern Ontario, Canada. Soil Sci Soc Am J. 2004;68:1394-402.

Wortmann CS, Drijber RA, Franti TG. One-time tillage of no-till crop land five years post-tillage. Agron J. 2010;102:1302-7. 